J. Egypt. Soc. Parasitol. (JESP), 44(3), 2014: 559 - 566

\title{
PRESENT STATUS OF PROTOZOAN PATHOGENS CAUSING WATER-BORNE DISEASE IN NORTHERN PART OF EL-MINIA GOVERNORATE, EGYPT
}

By

\author{
REFAAT M.A. KHALIFA ${ }^{1 *}$, AZZA K. AHMAD ${ }^{2}$, EKHLAS H. ABDEL-HAFEEZ ${ }^{2}$ \\ AND FADIA A. MOSLLEM ${ }^{3}$ \\ Departments of Parasitology, Faculty of Medicine, Assuit ${ }^{1}$ and El- Minia ${ }^{2}$ Universities \\ and Public Health and Preventive Medicine ${ }^{3}$, El-Minia University, Egypt \\ ('Correspondence to Prof. Khalifa E-mail: <rkhalifa_eg@yahoo.com)
}

\begin{abstract}
Little is known about the role of different water supplies in the diversity and public health significance of pathogenic protozoan parasites. Most of these organisms have been ubiquitous in waters worldwide. The numbers of waterborne infections indicate a significant risk for their transmission even by drinking water. Hence, a total of 336 water samples were collected during 2009-2013 from different water sources from different areas of northern part of El-Minia Governorate, Egypt and were investigated for pathogenic protozoa. They were examined by direct microscopy followed by Modified ZiehlNeelsen and Giemsa stains. 140 samples (41.7\%) were positive (statistically significant; $\mathrm{P}$ value $\mathrm{P}<0.0003)$. Prevalence rates were in Summer (66.7\%), Spring (51.1\%), Fall $(26.2 \%)$ and Winter $(22.6 \%)$. These data were statistically significant $(\mathrm{P}<0.0001)$. The commonest protozoa detected as a single infection was Cryptosporidium sp. (53.17\%) found in all water supplies, followed by Blastocystis hominis (15.87\%), Cyclospora caytenensis (11.9\%), Entamoeba histolytica/ dispar (8.73\%) Giardia lamblia (6.35\%) and Naegleria sp., (3.97\%). Moreover, there were 14 samples with mixed parsitic infection: they were Cryptosporidium sp. and B. hominis in six samples, Cryptosporidium sp. and C. caytenensisin five samples and Cryptosporidium sp. and E. histolytica/dispar in three samples. The most common contaminated water source was ponds where 32 samples $(66.7 \%)$ were positive followed by canal water 30 samples $(62.5 \%)$.
\end{abstract}

The results were discussed and the recommendations were offered.

Key words: Water samples, pathogenic protozoa, El- Minia Governorate.

\section{Introduction}

Water plays an important role in the transfer of many pathogenic microorganisms. Waterborne diseases are transmitted through contact with or consumption of infected water. Microorganisms that cause waterborne diseases are viruses, bacteria, protozoa, and helminthes. In Egypt, waterborne diseases represent a public health problem as the majority of rural population obtains their water supply from unprotected streams and ground water. Moreover, the control of waterborne diseases transmission is actually difficult, as certain pathogens, such as Cryptosporidium, are highly resistant to many traditional processes used for disinfection of water. In this study we will stress on protozoan parasites as one of the most important causes of the water-borne diseases. Some protozoan parasites such as Cryptosporidium sp., Cyclospo- ra cayetanensis, and Giardia lamblia were responsible for emerging cases of contaminated water (Céline et al, 2009). More than 160 waterborne outbreaks of cryptosporidiosis were reported worldwide in the last ten years (Carmena et al, 2006). The first $C$. cayetanensis waterborne outbreak was described in 1990 (Ortega and Sanchez, 2010). WHO (2011) confirmed the detection of $C$. cayetanensis, Microsporidia, Isospora belli and $C$. parvum in drinking water. Besides, Giardia is one of the commonest causes of waterborne diseases for over 30 years (Briancesco and Bonadonna, 2005). Additionally, cases of acanthamoebic keratitis have been reported due to use of tap water in preparing solutions for washing contact lenses. In El-Minia Governorate the percentage of such pathogenic protozoa has been documented in humans (Abdel-Hafeez et al, 
2012). However, very few epidemiological surveys have been conducted on the occurrence of these protozoa in water used for human consumption in this Governorate. Therefore, this paper aims to outline the prevalence of the pathogenic protozoan parasites that cause waterborne infection in the northern part of El-Minia Governorate, Egypt, as a pioneer milestone in the future plans for the provision of clean water supply for the community; which is the target of many recent studies (Anuar et al, 2013).

\section{Materials and methods}

Collection of water samples: The present work is a longitudinal descriptive study conducted in the northern part of El-Minia Governorate, in Upper Egypt, $234 \mathrm{Km}$ south to Cairo. A total of 336 samples of water have been collected from six cities of the northern part of El-Minia Governorate (Tab.3a). Samples were collected from seven different types of water (River Nile, waterworks, tap water, water pumps, water tanks, ponds and canal water) from each city. Eight samples were collected from each source, two samples in each season; Spring (May), Summer (August), Fall (October) and Winter (January) of 2009-2013 (56 samples from each city) to avoid seasonal fluctuations in oocyst contamination.

Sample processing: Each water sample was $10 \mathrm{ml}$ in volume. Samples were transmitted immediately after collection to the laboratory of Parasitology Department, Faculty of Medicine, El-Minia University for examination. Water samples were processed within 12 hours after collection.

Filtration method: Water samples were subjected to filtration using membrane filter dissolution method (Aldom and Chagla, 1995). They were filtered through a mesh sieve to remove the large particles and then concentrated by filtration on cellulose- acetate filters $(0.8 \mu \mathrm{m}$ pore size, Nuclepore Whatman, NJ, USA). The filtrate was put in $15 \mathrm{ml}$ centrifuge tubes and centrifuged at a speed of $3000 \mathrm{~g}$ for $10 \mathrm{~min}$. The supernatant was decanted and the pellets were subjected to the following: 1) Direct microscopic examination through saline and iodine wet mount smears. 2) Fixation and smear preparations where pellets were mixed with $10 \mathrm{ml}$ of fixation buffer (sodium-acetate acetic acid formalin, SAF) and incubated for $1 \mathrm{~h}$ to be fixed. The suspension was centrifuged at $2,000 \mathrm{~g}$ for $5 \mathrm{~min}$. Two smears were dried in air, fixed with methanol, stained by Modified Ziehl-Neelsen stain) (El Shazly et al, 2006) and Giemsa stain (Garcia, 2001).

Statistical analysis: Statistical Package of SPSS version 16 for windows was used. Descriptive statistics were calculated. For qualitative data, $\chi 2$-test and $\mathrm{Z}$ test were used for proportions. A significant $P$-value was considered when it was less than 0.05 .

\section{Results}

The results are illustrated in tables (1-5)

Sampling places and the number of the positive samples for parasites: One hundred and forty samples $(41.7 \%)$ out of 336 samples were diagnosed positive for parasitic infections. It has been found that BeniMazar City had highest rate of contamination $(58.9 \%)$ while El-Minia City had the lowest rate $(21.4 \%)$. These data were statistically significant ( $\mathrm{P}$ value $<0.0003$ ).

Seasonal variations of parasitic infections at different periods of year: Fifty six $(66.7 \%)$ samples were diagnosed positive in summer, $43(51.1 \%)$ samples were positive in spring. On the other hand, 22 (26.2\%) samples were diagnosed positive in fall and 19 (22.6\%) samples were diagnosed positive in winter (Tab. 2). These results were statistically significant $(\mathrm{P}<0.0001)$.

The prevalence of protozoan parasites detected is shown in (Tabs.1, 3a, b). The most common protozoa detected as a single infection was Cryptosporidium sp. (53.17\%), followed by Blastocystis sp. (15.87\%), Cyclospora caytenensis (11.9\%), E. histolytical dispar (8.73\%), Giardia lamblia (6.35\%) and Naegleria sp, (3.97\%).

There were 14 samples with mixed parasitic infection: Cryptosporidium sp. and Blastocystis sp. in six samples, Cryptosporidium 
sp. and C. caytenensis in five samples and Cryptosporidium sp. and E. histolytica/ dispar in three samples

Relation between the type of protozoan parasites detected and the type of water collected: Prevalence of protozoan parasites detected from different water sources is shown (Tab. 4). The commonest water source contaminated with protozoan para-

\section{Discussion}

Lack of access to healthy water is one of the most important problems that the majority of the world's population is facing. Contamination of drinking water with protozoan pathogens threats millions of people in developing world (WHO, 2011). The problem is particularly seen in rural Egyptian villages (Khairy et al, 1982). The main source of water in Egypt is the Nile River and this water is affected by many polluting activities such as sewage and industrial discharge, human activities and run-off from agricultural fields (El-Shazly et al, 2007). Water-borne outbreaks caused by Cryptosporidium sp., $C$. caytenensis, B. hominis and G. lamblia have been documented not only from Egypt but also worldwide even in developed countries (Dolejs et al, 2000 in Czech drinking water, Tsushima et al, 2001; Hashimoto et al, 2002 in Japan, Briancesco and Bonadonna, 2005 in Italy; Karanis et al, 2006 in Russia and Bulgaria, Céline et al, 2009 in France).

In the present study, the most common protozoa detected in different types of water as a single infection was Cryptosporidium sp. $(47.8 \%)$, followed by Blastocystis sp. (14.3\%), C. caytenensis (10.7\%), E. histolyticaldispar (7.9\%), G. lamblia (5.8\%) and Naegleria sp. (3.6\%). Moreover, there were 14 samples with mixed infections: Cryptosporidium sp. and Blastocystis sp. in six samples (4.3\%), Cryptosporidium $\mathrm{sp}$. and $C$. caytenensis in five samples (3.6\%), and Cryptosporidium sp. and E. histolytica/dispar in three samples $(2.1 \%)$

In this study, Cryptosporidium sp. oocysts were consistently detected in almost all types of water samples collected. The high sites was ponds where 32 samples $(66.7 \%)$ were positive followed by canal water 30 samples $(62.5 \%)$. These results were statistically significant $(\mathrm{P}<0.0001)$. The prevalence of the protozoan parasites detected from the different sources of water is shown in (Tab.5) which illustrates that Cryptosporidium sp. could be detected from all water sources.

occurrence of Cryptosporidium sp. in the water sources can be explained by the oocysts being resistant to disinfection. Moreover, Cryptosporidium oocysts are not inactivated by chlorination practices generally applied in the production of drinking-water. This result matched with other studies done by Carmena et al. (2006); El Shazly et al. (2007). In this connection, Chauret et al. (2001) recommended Chlorine dioxide for better cryptosporidial inactivation in water. In Egypt, sewage is subjected to minimal treatment and effluent is discharged into Nile River, lakes and seas (El Shazly et al, 2007). Reservoir animal hosts may be of utmost importance in contaminating drinking waters in Egypt. Thus, El-Khodery and Osman (2008) found $14.9 \%$ of buffalo calves less than 3 months age were infected with Cryptosporidium spp. in middle Egypt, El-Madawy et al. (2010) detected cryptosporidial infection among stray dogs in ElBehira Province and pointed out to the existence of a genotype that may play an important role as a source of human and farm animal cryptosporidiosis through drinking water contamination, Hassanain et al. (2011) illustrated the high prevalence of Cryptosporidium parvum in calves in El-Behira Province and pointed out to the possible zoonotic transmission between calves and humans in that region, Shaaban et al. (2011) reported the occurrence of cryptosporidiosis in native Egyptian quails and recommended fecal control of these birds and Amer et al. $(2013 a, b)$ discussed the public health potential of Cryptosporidium spp. in Egyptian water buffaloes and concluded that the commonly occurrence of $C$. parvum IId subtype 
in both buffalo calves and humans highlights the potential role of zoonotic transmission in the epidemiology of cryptosporidiosis. Moreover, Fayer et al. (2006) demonstrated the risk of human beings cryptosporidial infection through drinking water contaminated by the feces of youg diary cattle in USA. Therefore, future studies are recommended to determine the risk of zoonosis in waterborne infections but this also requires the assessment of the viability and infectivity of oocysts detected and the use of molecular methods which add value to performancebased morphologic methods; as many forms detected in water may originate from species/genotypes that are not infectious to humans (Quintero-Betancourt et al, 2003; Weintraub, 2006; Smith and Nichols, 2010). El-Temsahy et al. (2014) in Alexandria proved that cryptosporidia and cyclosporidia of freshwater fishes are not infectious to humans.

In this study, six tap water samples were contaminated with cryptosporidial oocysts, $(12.5 \%)$ out of 48 samples which are in accordance with observations by several studies; in Egypt (El Shazly et al, 2007) and in Spain (Carmena et al, 2006). In controversy, Nishi and others could not detect any Cryptosporidium in public treated water of Bolisista, Brazil (Nishi et al., 2009 a,b).

Blastocystis sp. was also detected in $16.9 \%$ of the water samples collected. This finding was in agreement with the data obtained by Leelayoova et al. (2008). They found that Blastocystis prevalence was $18.9 \%$ in school children of a rural community in Thailand and this infection came from drinking water. Waterborne transmission of blastocystosis had been suggested by a number of epidemiologic studies (Suresh et al, 2005; Li et al, 2007; Leelayoova et al, 2008). Furthermore, Ithoi et al. (2011) reported the occurrence of Blastocystis in two rivers located in recreational areas in Malaysia. Yan et al. (2007) indicated molecular-based evidence supporting the zoonotic potential of waterborne transmission of Blastocystis sp. sub- type 5 from pigs and Lee et al. (2012) reported Blastocysis sp. subtype 4 in buffalos and pigs in Nepal and blamed it as a waterborne zoonosis for human blastocystosis.

In the present work, $C$. cayetanensis was detected in $13.0 \%$, which concurred with Nimri (2003) in Jordan who reported that its oocysts were detected in the sediment of water in home storage tanks of patients with diarrhea. Water-borne $C$. caytenensis transmission was reported by few studies (Ortega and Sanchez 2010; Ithoi et al, 2011, WHO, 2011).

Giardiasis has been associated with drinking-water supplies over the past 30 years (Briancesco and Bonadonna, 2005) as the commonest cause of waterborne outbreaks since its cysts are more resistant to chlorine treatment, but not as resistant as Cryptosporidium oocysts (WHO, 2011). G. lamblia (5.2 \%) was detected but lower than Cryptosporidium spp. (52.6\%). This result mismatched with that obtained in some abroad countries by (Briancesco and Bonadonna, 2005; Hörman et al, 2004). Bednarska et al. (1998) found $14 \%$ of calves infected with Giardia sp. and stressed their role as reservoirs for human infection..

In the current study, E. histolyticaldispar $(9.0 \%)$ was detected in water samples from fecally contaminated ponds and canal water where water is untreated and fecally contaminated. Transmission of amoebiasis by water is common in developing countries (ElSzhazly et al., 2007). Moreover, Ximénez et al. (2011) stated that the asymptomatic cyst passers and the intestinal amoebiasis patients are the transmitters; they excrete cysts in their feces, which can contaminate food and water sources.

In Egypt, the prevalence of Cryptosporidium sp. and G. lamblia positive water samples was reported in El-Gharbia Governorate (Antonios et al, 2001), in Abo-El Nomros and El Hawamdia, Giza Governorate (Ali et $a l, 2004)$, in El-Dakahlia Governorate (El Shazly et al, 2007), and in Ismailia Governorate (Rayan et al, 2009) and in Alexandria 
Governorate (Khalifa et al, 2011). This is not surprising as these protozoan parasites are usually connected with poor sanitation. Contaminated water passes freely through water treatment plants because cryptosporidial oocysts in particular are not readily killed by chlorine and filtration may be ineffectual or non-existant.

In the present study, seasonal distribution of protozoan infection proved to be significantly highest in summer $(66.7 \%)$; these results agreed with Keeley and Faulkner (2008). It is obvious that hotness, humidity and stagnation of water increase the incidence of parasites in water. Seasonal peaks of human infection with Cryptosporidium have been reported in North America in Spring or late Summer, in Australia during the Summer, in Germany in late Summer, and in Central America during the rainy season. Hashimoto et al. (2002) advised close management of water supplies in the winter when the temperature is low and Keeley and Faulkner (2008) reported peaks of protozoan water contamination in Spring and late $\mathrm{Au}-$ tumn or early Winter in the United Kingdom and Ireland.

\section{Conclusion}

The present work exhibited the update prevalence of pathogenic protozoa in different water supplies in northern part of El-Minia Governorate as a pioneer milestone in the future plans for the provision of clean water supply for the community. The presence of cryptosporidial oocysts in all water supplies; even tap drinking water is hazardous and this may be due to its being least resistant to regular water disinfection practice and this represents a potential risk to public health and water industries. The poor microbial quality of the water supplies in El-Minia Governorate may be due to improper operational skills and management of the various water treatment plants. Hence, an additional water treatment steps are recommended in order to reduce waterborne diseases. Future studies are recommended to determine the risk of zoonosis in waterborne infections.
This also requires the assessment of the viability and infectivity of protozoa detected and the use of molecular methods which add value to performance-based morphologic methods; as many forms detected in water may originate from species/genotypes that are not infectious to humans.

\section{References}

Abdel-Hafeez. EH, Ahmed, AK, Ali, BA, Mosallem, FA, 2012: Opportunistic parasites among immunosuppressed children in Minia district, Egypt. Korean J. Parasitol. 50, 1:57-62.

Aldom, JE, Chagla, AH, 1995: Recovery of Cryptosporidium oocysts from water by a membrane filters dissolution method. Lett. Appl. Microbiol. 20:186-7.

Ali, MA, Al-Herrawy, AZ, El-Hawaary, SE, 2004: Detection of enteric viruses, Giardia and Cryptosporidium in two different types of drinking water treatment facilities. Water Res. 38, 18: 3931-9.

Amer, S, Zidan, S, Adamum H, Ye, J, Roellig, $D$, et al, 2013a: Prevalence and characterization of Cryptosporidium spp. in dairy cattle in Nile River delta provinces, Egypt. Exp. Parasitol. 135, 3:518-23.

Amer, S, Zidan, S, Feng, Y, et al, 2013b: Identity and public health potential of Cryptosporidium spp. in water buffalo calves in Egypt. Vet. Parasitol. 191:123-7.

Antonios, SA, Salem, SA, Khalifa, EA, 2001: Water pollution is a risk factor for Cryptosporidium infection in Gharbia Governorate. J Egypt Soc Parasitol, 31, 3:963-4.

Anuar, T, Ghani, M, Azreen, S, et al, 2013: Blastocystis infection in Malaysia: Evidence of waterborne and human to human transmissions among the Proto-Malay, Negrito and Senoi tribes of Orang Asli. Parasit. Vectors 6:40-7.

Bednarska, M, Bajer, A, Sinski, E, 1998: Calves as a potential reservoir of Cryptosporidium parvum and Giardia sp. Ann. Agric. Environ. Med. 5, 2:136-8.

Briancesco, R, Bonadonna, L, 2005: An Italian study on Cryptosporidium and Giardia in waste water, fresh water and treated water. Environ. Monit. Assess. 104:445-57.

Carmena, D, Aguinagalde, X, Zigorraga, $\mathrm{C}$, et al, 2006: Presence of Giardia cysts and Cryptosporidium oocysts in drinking water supplies 
in northern Spain. J. Appl. Microbil. 102:61929.

Céline, M, Aurélien, D, Sylvie, G, ChristelleLaurent, M, 2009: Monitoring of Cryptosporidium and Giardia river contamination in Paris area. Water Res, 43, 1:211-17.

Chauret, C, Radziminski, C, Lepuil, M, et al, 2001: Chlorine Dioxide inactivation of Cryptosporidium parvum oocysts and bacterial spore indicators. Appl. Environ. Microbiol. 67, 7:2993-3001.

Dolejs, P, Ditrich, O, Macula, T, et al, 2000: Monitoring of Cryptosporidium and Giardia in Czech drinking water. Scrift. Ver. Wasser-Bun den Lufthyge 105:147-51.

El-Khodery, S, Osman, S, 2008: Cryptosporidiosis in buffalo calves (Bubalus bubalis): prevalence and potential risk factors. Trop Anim Hlth. Prod. 40, 6:419-26.

El-Madawy, R, Khalifa, N, Khater, H, 2010: Detection of cryptosporidial infection among Egyptian stray dogs by using Cryptosporidium parvum wall protein gene. Bulg. J. Vet. Med. 13, 2:104-10.

El Shazly, AM, Awad, SE, Soltan, DM, Sadek, GS, Khalil, HH, Morsy TA, 2006: Intestinal parasites in Dakahlia governorate, with different techniques in diagnosing protozoa. J. Egypt. Soc. Parasitol. 36:1023-34.

El Shazly, AM, Elsheikha, HM, Soltan, DM, Mohammad, KA, Morsy, TA, 2007: Protozoal pollution of surface water sources in Dakahlia governorate. J. Egypt. Soc. Parasitol. 37, 1:5164.

El-Temsahy, M, Kerdany, E, Diab, R, et al. 2014: Comparison between human and fish Cryptosporidium and Cyclospora. PUJ, 7, 1:1-9.

Fayer, R, Santin, M, Trout, J, Greiner, E, 2006: Prevalence of species and genotypes of Cryptosporidium found in 1-2 year-old cattle in the eastern United States. Vet. Parasitol. 135: 105-12.

Garcia, LS, 2001: Diagnostic Medical Parasitology. $4^{\text {th }}$ ed., Washington DC, ASM Press.

Hashimoto, A, Kunikane, S, Hirata, T, 2002: Prevalence of Cryptosporidium oocysts and Giardia cysts in the drinking water supply in Japan. Water Res. 36:519-26.

Hassanain, M, Khalil, F, Abdel-Razik, K, Shabaan, R, 2011: Prevalence and molecular discrimination of Cryptosporidium parvum in calves in Behira Province, Egypt. Res. J. Parasitol. 6:101-8.

Hörman, A, Rimhanen-Finne, R, Maunula, L, et al, 2004: Campylobacter spp., Giardia spp. Cryptosporidium spp. noroviruses, and indicator organisms in surface water in southwestern Finland, 2000-2001. Appl. Environ. Microbiol. 70: 87-95.

Ithoi, I, Jali, A, Mak, JW, et al, 2011: Occurrence of Blastocystis in water of two rivers from recreational areas in Malaysia. J. Parasitol. Res. Article ID: 123916: 1-8.

Karanis, P, Sotiriadou, I, Kartashev, V, et al, 2006: Occurrence of Giardia and Cryptosporidium in water supplies of Russia and Bulgaria. Environ. Res. 102:260-71.

Keeley, A, Faulkner, BR, 2008: Influences of land use and watershed characteristics on protozoa contamination on potential drinking water resources reservoir. Water Res. 42, 10/11:280313.

Khairy, A, El-Sebaie, O, Abdel Gawad, A, ElAttar, 1, 1982: The sanitary condition of rural drinking water in a Nile Delta village. 1. Parasitological assessment of 'zir' stored and direct tap water. J. Hyg. Camb. 88:57-61.

Khalifa, AM, Ibrahim, IR, Said, DE, Aleem, EA, Nabil, RA, 2011: Cryptosporidium and Giardia in water in Alexandria: Detection and evaluation of viability by flow cytometry and different stains. PUJ, 4, 2:155-64.

Lee, L, Chye, T, Karmacharya, B, Govind, S, 2012: Blastocystosis sp.: Waterborne zoonotic organism, a possibility? Parasit. Vectors 28, 5: $130-8$

Leelayoova, S, Siripattanapipong, S, ThathaIsong, U, et al, 2008: Drinking Water: A possible source of Blastocystis spp. subtype 1 infection in school children of a rural community in Central Thailand. Am. J. Trop. Med. Hyg. 79, 3:401-6.

Li, LH, Zhou, ZN, Du, ZW, et al, 2007: Molecular epidemiology of human Blastocystis in a village in Yunnan province, China. Parasitol. Int. 56:107-12.

Nimri, LF, 2003: Cyclospora cayetanensis and other intestinal parasites associated with diarrhea in a rural area of Jordan. Int Microbiol, 6:131-5.

Nishi, L, Baesso, M L, Santana, RG, et al, 2009a: Investigation of Cryptosporidium spp. and Giardia spp. in a public water-treatment system. Zoono. Pub. Hlth. 56:221-8. 
Nishi, L, Bergamasco, R, Toledo, MJO, et al, 2009b: Giardia Spp and Crypto-sporidium Spp. In: the lvai indigenous Land. Brazil Vector-borne Zoon. Dis. 9, 5:543-7.

Ortega, YR, Sanchez, R, 2010: Update review on Cyclospora cayetanensis, a food-borne and waterborne parasite. Clin. Microbiol. Rev. 23, 1:218-34.

Quintero-Betancourt, W, Gennaccaro, A, Scott, T, Rose, J, 2003: Assessment of methods for detection of infectious Cryptosporidium oocysts and Giardia cysts in reclaimed effluents. Appl. Environ. Microbiol. 69, 9:5380-8.

Rayan, HZ, Eida, OM, El-Hamshary, EM, Ahmed, SA, 2009: Detection of human Cryptosporidium species in surface water sources in Ismailia using PCR. PUJ, 2, 2: 119-26.

Shaaban, M, Khalil, A, Abu El-Ezz, M, 2011: Cryptosporidiosis and toxoplasmosis in native quails in Egypt. Res. J. Vet. Sci. 4-2:30-6.

Smith, H, Nichols, R, 2010: Cryptosporidium: detection in water and food. Exp. Parasitol. 124, 1:61-79.
Suresh, K, Smith, HV, Tan, TC, 2005: Viable Blastocystis cysts in Scottish and Malaysian sewage samples. Appl. Environ. Microbiol. 71: 5619-20.

Tsushima, Y, Karanis, P, Kadama, T, et al, 2001: Detection of Cryptosporidium parvum oocysts in environmental water in Hokkaido, Japan. J. Vet. Med. Sci. 40, 3: 233-6.

Weintraub, JM, 2006: Improving Cryptosporidium testing methods: a public health perspective. J. Water Hlth. 4, 1:S23-6.

WHO, 2011: Guidelines for Drinking-Water Quality, Microbial Aspects. Geneva.

Ximénez, C, Morán, P, Rojas, L, Valadez, A, Gómez, A, 2011: Novelties on amoebiasis: a neglected tropical disease. J. Glob. Infect. Dis. 3, 2:166-74.

Yan, Y, Su, S, Lai, X, et al, 2007: Blastocystis sp. subtype 5: A possible zoonotic genotype. Parasitol. Res. 10, 16:1527-32.

Table 1: Protozoan parasites detected in northern part of El-Minia Governorate

\begin{tabular}{|l|c|c|c|c|}
\hline Single Protozoan parasites & No. & $\%$ & Z & P value \\
\hline Cryptosporidium spp. & 67 & 53.17 & 07 & 0.2 \\
\hline Blastocystis hominis & 20 & 15.87 & 10.4 & 0.0001 \\
\hline Cyclospora caytenensis & 15 & 11.9 & 12.2 & 0.0001 \\
\hline E. histolytica/dispar & 11 & 8.73 & 14.4 & 0.0001 \\
\hline Giardia lamblia & 8 & 6.35 & 20.1 & 0.0001 \\
\hline Acanthamoeba sp. & 5 & 3.97 & 26.4 & 0.0001 \\
\hline Total & 126 & \multicolumn{3}{|l}{100} \\
\hline
\end{tabular}

Chi2 $=17.8, \mathrm{DF}=5, \mathrm{P}<0.0003$

Table 2: Seasonal variations of water sources protozoan contamination

\begin{tabular}{|l|lc|lc|lc|}
\hline \multirow{2}{*}{ Period of the year } & \multicolumn{2}{|c|}{ Positive } & \multicolumn{2}{|c|}{ Negative } & \multicolumn{2}{c|}{ Total } \\
& $\mathrm{N}$ & $\%$ & $\mathrm{~N}$ & $\%$ & $\mathrm{~N}$ & $\%$ \\
\hline Summer & 56 & 66.7 & 28 & 33.3 & 84 & 100 \\
\hline Spring & 43 & 51.1 & 41 & 48.8 & 84 & 100 \\
\hline Fall & 22 & 26.2 & 62 & 73.8 & 84 & 100 \\
\hline winter & 19 & 22.6 & 65 & 77.3 & 84 & 100 \\
\hline Total & 140 & 41.7 & 196 & 58.3 & 336 & 100 \\
\hline
\end{tabular}

Chi2 $=45.5, \mathrm{DF}=3, \mathrm{P}<0.0001$

Table 3a: Single Protozoa detected in different Northern parts of El-Minia Governorate.

\begin{tabular}{|c|c|c|c|c|c|c|c|c|}
\hline Protozoan parasites. & $\begin{array}{l}\text { R. Nile } \\
\text { No. } \%\end{array}$ & $\begin{array}{l}\text { W. works } \\
\text { No. } \%\end{array}$ & $\begin{array}{l}\text { Tap } \\
\text { No. } \%\end{array}$ & $\begin{array}{l}\text { Pumps } \\
\text { No. } \%\end{array}$ & $\begin{array}{l}\text { Tanks } \\
\text { No. } \%\end{array}$ & $\begin{array}{l}\text { Ponds } \\
\text { No. } \%\end{array}$ & $\begin{array}{l}\text { Canal } \\
\text { No. } \%\end{array}$ & No. $\%$ \\
\hline Cryptosporidium sp. & $15 \quad 18.5$ & $10 \quad 12.4$ & $\begin{array}{ll}6 & 7.4\end{array}$ & 9911.1 & 1214.8 & $17 \quad 20.9$ & 1214.8 & 81100 \\
\hline B. hominis & 23.1 & 15.4 & $\begin{array}{ll}0 & 0.0 \\
\end{array}$ & $\begin{array}{ll}0 & 0.0 \\
\end{array}$ & $4 \quad 15.4$ & $7 \quad 26.9$ & 19.2 & 26100 \\
\hline C. caytenensis & 15.0 & 315.0 & 0.0 & 5.0 & $4 \quad 20.0$ & 25.0 & $4 \quad 20.0$ & 20100 \\
\hline E. histolytica/dispar & 14.3 & 00.0 & 0.0 & 0.0 & $\begin{array}{ll}1 & 07.1 \\
\end{array}$ & 35.7 & 42.9 & 14100 \\
\hline G. lamblia & 37.5 & 00.0 & 0.0 & 0.0 & 00.0 & 25.0 & 37.5 & 100 \\
\hline Acanthamoeba sp. & 00.0 & $\begin{array}{ll}0 & 00.0 \\
\end{array}$ & $\begin{array}{ll}0 & 0.0 \\
\end{array}$ & $\begin{array}{ll}0 & 0.0 \\
\end{array}$ & 00.0 & 20.0 & 60.0 & 100 \\
\hline Total & 2918.82 & 1711.04 & 74.55 & 106.49 & 2113.64 & 3724.03 & 3321.43 & 154100 \\
\hline
\end{tabular}


Table 3b: Mixed Protozoan parasites detected in northern parts of El-Minia Governorate.

\begin{tabular}{|l|l|l|l|l|}
\hline Grand total & No. (140) & $\%(100 \%)$ & $\mathrm{Z}$ & P-value \\
\hline Total single & 126 & $90 \%$ & \multirow{2}{*}{15.7} & 0.0001 \\
\hline Total mixed & 14 & $10 \%$ & & \\
\hline
\end{tabular}

Table 4: Prevalence of pathogenic protozoan parasites in different water sources

\begin{tabular}{|l|lr|rr|rr|}
\hline \multirow{2}{*}{ Type of water } & \multicolumn{2}{|c|}{ Positive } & \multicolumn{2}{c|}{ Negative } & \multicolumn{2}{c|}{ Total } \\
examined & No. & $\%$ & No. & $\%$ & No. & $\%$ \\
\hline River Nile & 26 & 54.2 & 22 & 45.8 & 48 & 100 \\
\hline Waterworks & 16 & 33.3 & 32 & 66.7 & 48 & 100 \\
\hline Tap water & 6 & 12.5 & 42 & 87.5 & 48 & 100 \\
\hline Pumps water & 10 & 20.8 & 38 & 79.2 & 48 & 100 \\
\hline Tanks water & 20 & 41.7 & 28 & 58.3 & 48 & 100 \\
\hline Ponds & 32 & 66.7 & 16 & 33.3 & 48 & 100 \\
\hline Canal water & 30 & 62.5 & 18 & 37.5 & 48 & 100 \\
\hline Total & 140 & 41.7 & 196 & 58.3 & 336 & 100 \\
\hline
\end{tabular}

$\mathrm{Chi}^{2}=50.7, \mathrm{DF}=6, \mathrm{P}<0.0001$

Table 5: Prevalence of protozoan parasites detected from different water sources collected from Northern Parts of El-Minia Governorate.

\begin{tabular}{|l|cc|cc|cc|}
\hline \multirow{2}{*}{ City } & \multicolumn{2}{|c|}{ Negative } & \multicolumn{3}{|c|}{ Positive } & \multicolumn{2}{c|}{ Total } \\
& $\mathrm{N}$ & $\%$ & $\mathrm{~N}$ & $\%$ & $\mathrm{~N}$ & $\%$ \\
\hline Maghagha & 31 & 55.4 & 25 & 44.6 & 56 & 100 \\
\hline El-Edwa & 36 & 64.3 & 20 & 35.7 & 56 & 100 \\
\hline Beni-Mazar & 23 & 41.1 & 33 & 58.9 & 56 & 100 \\
\hline Matai & 30 & 53.6 & 26 & 46.4 & 56 & 100 \\
\hline Samalut & 32 & 57.2 & 24 & 42.8 & 56 & 100 \\
\hline El-Minia & 44 & 78.6 & 12 & 21.4 & 56 & 100 \\
\hline Total number & 196 & 58.3 & 140 & 41.7 & 336 & 100 \\
\hline
\end{tabular}

